Since the technique of testing at Hammersmith might have been at fault, we selected 44 sera from those available in sufficient volumes to be retested at Midhurst. The batch included equal proportions of sera from the presumptively positive group 2 and the presumptively negative groups 3 and 4 chosen so that there would be similar proportions of those found to be positive or negative in the Hammersmith tests. These sera were sent coded to Midhurst. Of the 22 group 2 sera from tuberculous patients 11 were positive $(>1 / 125)$ at Hammersmith and eight were positive $(\geqslant 1 / 120)$ at Midhurst. Of the 22 sera in groups 3 and 4 from contacts and controls eight were positive at Hammersmith and nine at Midhurst. For the entire comparison $r=0.54$; the results obtained at Hammersmith and Midhurst agreed as positive or negative for 38 of the 44 sera. Thus the failure of the Hammersmith tests to distinguish between group 2 and groups 3 and 4 could not be attributed to differences in the methods used in the two laboratories.

TABLE III-Agglutination test results on sera obtained before treatment and two months later from tuberculous patients

\begin{tabular}{|c|c|c|c|c|}
\hline \multirow{2}{*}{$\begin{array}{l}\text { 2-Month } \\
\text { titre }\end{array}$} & \multicolumn{3}{|c|}{ Pretreatment titre } & \multirow{2}{*}{ Tota } \\
\hline & 25 & 50 & 125 & \\
\hline $\begin{array}{r}\leqslant 25 \\
50 \\
\end{array}$ & $\begin{array}{l}7 \\
6 \\
\end{array}$ & $\begin{array}{l}5 \\
7\end{array}$ & 2 & $\begin{array}{l}12 \\
15\end{array}$ \\
\hline Total & 13 & 12 & 2 & 27 \\
\hline
\end{tabular}

In view of the claim that occasional patients with culture-positive tuberculosis might have an initial low titre in the test followed a few weeks later by a diagnostic rising titre, ${ }^{11}$ tests were carried out on group 5 sera, which were samples obtained two months after the start of chemotherapy from 27 patients whose pretreatment sera had low titres (group 2) (table III). There was no evidence of any change during the period: a titre of 50 or more was obtained in 14 pretreatment sera and in 15 taken at two months.

\section{Comment}

The similarity of the results of the agglutination test in patients with active pulmonary tuberculosis; in healthy contacts, whether or not they were positive on the Mantoux test; and in patients with non-tuberculous conditions indicates that the test has no value in diagnosing active tuberculosis and should not be requested for this purpose. This failure to confirm the claims from the Midhurst Medical Research Institute does not seem to be due to differences in the method used in the two laboratories since the results obtained at Midhurst and Hammersmith agreed reasonably well. In particular, the Midhurst laboratory found a similar number of negative results among the sera from patients with active tuberculosis and positive results among sera from the non-tuberculous controls.

\section{References}

${ }^{1}$ Middlebrook, G, and Dubos, R J, fournal of Experimental Medicine, 1948, 88, 521.

2 Parlett, R C, and Youmans, G P, American Review of Respiratory Disease, 1959, 80, 153.

3 Takahashi, Y, American Review of Respiratory Disease, 1962, 85, 708.

4 Wallace, R, et al, Canadian Medical fournal, 1966, 94, 947.

5 Duboczy, B O, and White, F C, American Review of Respiratory Disease, 1966, 94, 914.

${ }^{6}$ Cole, R V, Lazarus, A W, and Hedrick, H G, Applied Microbiology, 1972, 24, 525.

7 Affronti, L F, Fife, E H, and Grow, L, American Review of Respiratory Disease, 1973, 107, 822

${ }^{8}$ Nassau, E, Parsons, E R, and Johnson, G D, Fournal of Immunological Methods, 1975, 6, 261.

${ }^{9}$ Reggiardo, Z, and Middlebrook, G, American fournal of Epidemiology, 1975, 100, 477 .

${ }^{10}$ Nicholls, A C, Journal of Clinical Pathology, 1975, 28, 850.

11 Nicholls, A C, and Horsfield, K, Thorax, 1976, 31, 289.

12 Singapore Tuberculosis Service-British Medical Research Council, Lancet, 1975, 2, 1105.

\title{
Antipyrine, paracetamol, and lignocaine elimination in chronic liver disease
}

\author{
JOHN A H FORREST, N D C FINLAYSON， K K ADJEPON-YAMOAH， L F PRESCOTT
}

British Medical fournal, 1977, 1, 1384-1387

\section{Summary}

The plasma half lives of antipyrine, paracetamol, and lignocaine given by mouth were measured in 23 patients with stable chronic liver diseases of varying severity. Fifteen patients received all three drugs and 19 at least

\section{Gastrointestinal and Liver Service, Royal Infirmary, Edinburgh EH3 9YW}

JOHN A H FORREST, BSC, MRCP, senior registrar in gastroenterology N D C FINLAYSON, PHD, MRCP, consultant physician

University Department of Therapeutics, Royal Infirmary, Edinburgh EH3 9YW

K K ADJEPON-YAMOAH, PHD, MRCP, research fellow in clinical pharmacology (present address: Department of Pharmacology, University of Ghana Medical School, Accra, Ghana)

L F PRESCOTT, MD, FRCPED, reader in clinical pharmacology and consultant physician two. The half life of paracetamol was abnormally prolonged in nine out of 17 patients (mean 2.9 hours, normal 2.0 hours), of antipyrine in 10 out of 19 patients (mean 30.4 hours, normal 12.0 hours), and of lignocaine in 19 out of 21 patients (mean 6.6 hours, normal 1.4 hours). Prolongation of the half lives of all three drugs was significantly correlated with an increase of the vitamin- $K_{1}$ corrected prothrombin time ratio and a reduction in serum albumin concentration. There was no correlation with serum bilirubin concentration or serum alanine aminotransferase activity. This suggests that impaired drug elimination was related to depressed hepatic protein synthesis. Considerable prolongation of the half life of one drug was invariably associated with delayed elimination of the others. The half life of lignocaine, however, was always the most prolonged and was a highly sensitive indicator of hepatic dysfunction. The pharmacokinetic characteristics of a drug as well as the severity of liver disease should be taken into account when considering drug dosage in patients with chronic liver disease. 


\section{Introduction}

The liver is an important site of drug metabolism, and serious toxicity may occur in patients with chronic liver disease prescribed drugs in normal dosage, ${ }^{1}$ prolongation of the half life of many drugs extensively metabolised by the liver having been documented. ${ }^{2-6}$ On the other hand, some investigators have reported a normal rate of elimination of some drugs in certain patients with chronic liver disease. ${ }^{7-10}$ Possible reasons for these discrepancies are that insufficient attention has been given to the nature and severity of the underlying liver disease and to the pharmacokinetic characteristics of the drugs used. ${ }^{11}$

Antipyrine is commonly used to assess drug-metabolising capacity, and prolongation of its plasma half life has been reported in patients with decompensated liver disease. ${ }^{12} 13$ Prolongation of the plasma half life of antipyrine is often assumed to be associated with corresponding changes in the elimination of other drugs, but this has not been examined in patients with chronic liver disease. Furthermore, in healthy volunteers the half life of antipyrine cannot always be correlated with the half lives of other drugs. ${ }^{14-16}$

Our aim was to compare the plasma half-lives of antipyrine, paracetamol, and lignocaine in the same patients with different forms of chronic stable liver disease of varying severity and to relate the findings to biochemical indices of liver function. Paracetamol and lignocaine were chosen because, unlike antipyrine, they are widely used in clinical practice and have different primary routes of metabolism and different pharmacokinetic characteristics.

\section{Patients and methods}

We studied 23 patients admitted for investigation and treatment of chronic liver disease. Informed consent was obtained from all Table I gives the clinical details and diagnoses, which in all but three patients were established by biopsy or necropsy. The following indices of liver function were measured before the drugs were given: serum bilirubin and albumin concentrations, serum alanine aminotransferase (SGPT) and alkaline phosphatase activities, and the prothrombin time ratio (PTR). The respective normal values are 2-17 $\mu \mathrm{mol} / 1(0 \cdot 12-1 \cdot 0 \mathrm{mg} / 100 \mathrm{ml}), 36-47 \mathrm{~g} / 1,10-40 \mathrm{U} / 1,40-100 \mathrm{U} / 1$, and 1.3 or less. If the PTR was over 1.4 , vitamin $K_{1}(10 \mathrm{mg}$ intramuscularly) was given on two successive days, the PTR remeasured, and this vitamin- $\mathrm{K}_{1}$-corrected PTR used.

A complete drug history was taken, and whenever possible all drugs were stopped before the studies began. Ten patients had been taking drugs regularly: in case 4 bendrofluazide and spironolactone; in case 8 spironolactone and protriptyline; in case 9 bendrofluazide; in cases
7,13 , and 16 frusemide and spironolactone; in case 11 spironolactone; in cases 16 and 18 prednisolone; in case 20 cholestyramine and chlorpheniramine; and in case 21 pentobarbitone.

At the time of study all patients were stable in their optimal clinical state and none was in cardiac failure. Only one patient (case 13) had a raised blood urea concentration. Five patients (cases $8,11,12,13$, and 18) had ascites, and six (cases $2,4,7,9,13$, and 21) oesophageal varices. Two patients (cases 15 and 23) had previously undergone portosystemic shunt operations, the shunts being judged patent by a continuing absence of varices.

The test drugs were administered consecutively two to three days apart over 7-10 days and usually in the sequence lignocaine, antipyrine, paracetamol. The studies followed a similar pattern. After an overnight fast each drug was administered with $40 \mathrm{ml}$ of water in the following dosage: lignocaine hydrochloride $400 \mathrm{mg}$ (tablets); antipyrine $18 \mathrm{mg} / \mathrm{kg}$ (in solution); paracetamol $1.5 \mathrm{~g}$ (tablets). Food and fluids were withheld for two hours after ingestion. At least five blood samples were taken for estimation of drug concentrations over 24,48 , and 9 hours respectively.

The plasma was separated and stored frozen until the drug concentrations were determined by gas-liquid chromatography. ${ }^{17-19}$ Half lives of the drugs were calculated from the linear regression of the logarithms of the plasma concentrations against time by using the method of least squares. The plasma half lives of these three drugs in healthy people were reported previously. ${ }^{20-22}$ Abnormal prolongation of half life was defined as greater than 2 SD beyond the mean value in normal people.

\section{Results}

The mean plasma half life of each drug was prolonged in patients with liver disease compared with the mean values in healthy people (table II). The half life of lignocaine was prolonged to a much greater extent $(371 \%)$ than that of antipyrine $(153 \%)$ or paracetamol $(45 \%)$

The half life of lignocaine was abnormally prolonged in 19 out of 21 patients, of antipyrine in 10 out of 19 patients, and of paracetamol in

TABLE II-Mean half lives of paracetamol, antipyrine, and lignocaine in plasma $( \pm S D)$ in healthy people and patients with chronic liver disease

\begin{tabular}{|c|c|c|c|}
\hline & $\begin{array}{l}\text { Paracetamol } \\
\text { half life } \\
\text { (h) }\end{array}$ & $\begin{array}{l}\text { Antipyrine } \\
\text { half life } \\
\text { (h) }\end{array}$ & $\begin{array}{l}\text { Lignocaine } \\
\text { half life } \\
(\mathrm{h})\end{array}$ \\
\hline $\begin{array}{l}\text { Patients with chronic } \\
\text { liver disease } \\
\text { Healthy people }\end{array}$ & $\begin{array}{l}2.9 \pm 0.3 \\
2.0 \pm 0.4^{*}\end{array}$ & $\begin{array}{l}30 \cdot 3 \pm 6 \cdot 8 \\
12 \cdot 0 \pm 3 \cdot 5+\end{array}$ & $\begin{array}{l}6 \cdot 6 \pm 1 \cdot 1 \\
1 \cdot 4 \pm 0 \cdot 26 \pm\end{array}$ \\
\hline „Difference .. & 45 & 153 & 371 \\
\hline
\end{tabular}

${ }^{*}$ See ref ${ }^{22}$. †See ref ${ }^{21} .+$ See ref ${ }^{20}$.

TABLE I-Clinical and laboratory details of patients studied

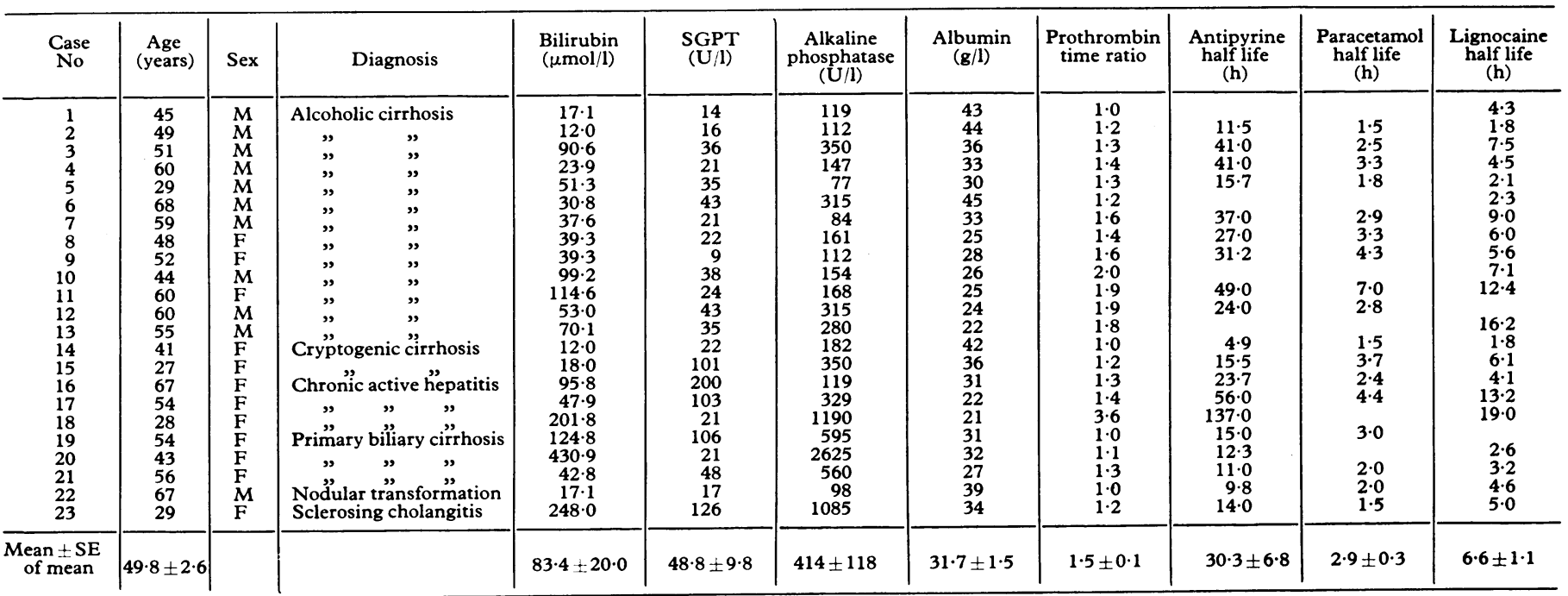


nine out of 17 patients. There were significant correlations between the half lives of all three drugs $(r \geqslant 0.73 ; P<0.01)$. Comparison of the plasma half lives of the drugs with the liver function values showed significant correlations between the half life of each drug and the serum albumin concentration $(r \geqslant 0.58 ; P<0.01)$ and PTR $(r \geqslant 0.64$; $\mathbf{P}<0.01)$ but not with serum bilirubin $(r \leqslant 0.16 ; \mathbf{P}>0.05)$, SGPT $(r \leqslant 0.17 ; P>0.05)$, or alkaline phosphatase $(r \leqslant 0.21 ; P>0.05)$.

In 13 patients either the serum albumin concentration or the PTR or both were normal. Two out of 11 of these patients had a prolonged half life of antipyrine, and two out of 10 a prolonged half life of paracetamol. In no instance was the increase pronounced (table III). In the other 10 patients both the serum albumin concentration and the PTR were abnormal; among these patients, six out of seven had a prolonged half life of paracetamol, and all eight tested a prolonged half life of antipyrine. In these patients the prolongation was considerable (table III).

TABLE III-Mean percentage increase in drug half lives in relation to serum albumin concentration and prothrombin time ratio $(P T R)$

\begin{tabular}{|c|c|c|c|c|}
\hline & & $\begin{array}{l}\text { Albumin and } \\
\text { PTR normal }\end{array}$ & $\begin{array}{l}\text { Albumin or } \\
\text { PTR abnormal }\end{array}$ & $\begin{array}{l}\text { Albumin and } \\
\text { PTR abnormal }\end{array}$ \\
\hline $\begin{array}{l}\text { Paracetamol } \\
\text { Antipyrine } \\
\text { Lignocaine }\end{array}$ & $\begin{array}{ll}. & \ldots \\
\ldots & \ldots\end{array}$ & $\begin{array}{r}12 \\
38 \\
190\end{array}$ & $\begin{array}{r}7 \\
27 \\
143\end{array}$ & $\begin{array}{l}100 \\
319 \\
638\end{array}$ \\
\hline
\end{tabular}

The half life of lignocaine was prolonged in five out of seven patients with a normal albumin concentration and PTR, but in all patients in whom one or both of these values were abnormal lignocaine elimination was abnormally slow (see figure). In all instances prolongation of the lignocaine half life was considerable (table III). When both the serum albumin and PTR were abnormal, lignocaine was eliminated at only one-sixth of the normal rate.

In the patients known to have taken compounds causing microsomal enzyme induction the drug half lives were not significantly different from those of others with a similar degree of liver dysfunction as assessed by routine liver function tests.

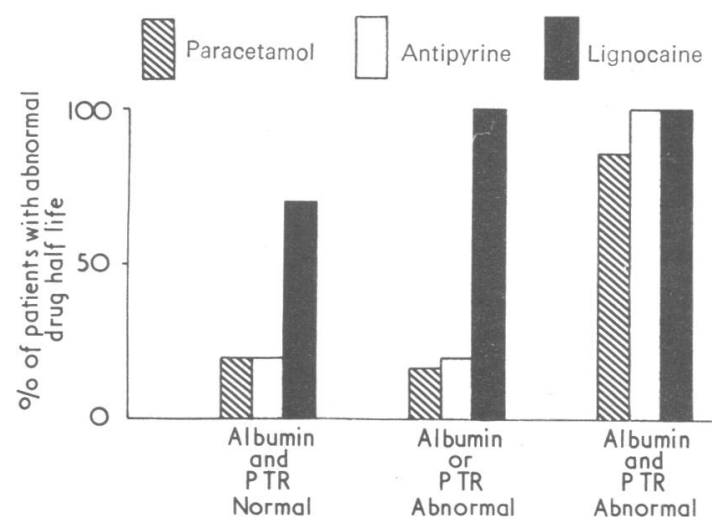

Relation of serum albumin concentration and prothrombin time ratio (PTR) to frequency of abnormal plasma half lives of paracetamol antipyrine, and lignocaine.

\section{Discussion}

Since many drugs are extensively metabolised by the liver it is important to know whether their elimination is abnormally slow in patients with chronic liver disease so that a reduction in dosage can be made to reduce the risk of accumulation and toxicity. Although the rate of elimination of antipyrine ${ }^{1213}$ is reduced in patients with chronic liver disease, simultaneous comparisons with other drugs do not seem to have been made. To ascertain whether the elimination of individual drugs might be different we have studied the rates of elimination of three drugs, each having a different primary route of metabolism (antipyrine, hydroxylation; paracetamol, conjugation; lignocaine, $\mathrm{N}$-dealkylation) and different pharmacokinetic properties (hepatic-extraction ratios: antipyrine 0.03 , paracetamol 0.15 , lignocaine 0.70 ), in patients with different forms of stable chronic liver disease.

The plasma half life of lignocaine was prolonged to a much greater extent than that of antipyrine, and paracetamol was affected least. Although there was a good correlation between the plasma half lives of all three drugs, minor prolongation of the antipyrine half life could be associated with severely impaired elimination of lignocaine and a normal paracetamol half life. Thus the half life of antipyrine is a poor indicator of the ability of patients with chronic liver disease to eliminate other drugs. The half lives of paracetamol and antipyrine were increased in $20^{\circ}$ of patients with a normal serum albumin concentration or PTR, although the mean increases over normal, of $10^{\circ}{ }_{0}$ and $33^{\circ}{ }_{0}$ respectively, are of little clinical importance in respect of the drug dosage that might be prescribed. Even when these two indices of liver function were normal the mean rate of lignocaine elimination was only $50^{\circ}$ of normal, some $70^{\circ}$ of patients having a prolonged half life. In contrast the half life of only one drug was normal in patients with an abnormal albumin concentration and PTR. Regardless of the serum albumin concentration or PTR, paracetamol elimination was always least affected, which might have been due to conjugation of the drug at extrahepatic sites such as the gastrointestinal mucosa, which is rich in glucuronyl transferase and aryl sulphatase.

Lignocaine elimination, in contrast, was always the most severely depressed, and in those patients with an abnormal serum albumin concentration and PTR was eliminated at only $16 \%$ of the normal rate. There are several possible explanations for this. Hepatic blood flow is often decreased in cirrhosis by portosystemic shunting, ${ }^{23}$ and this might have a much greater effect on the clearance of drugs with a high hepatic extraction ratio such as lignocaine than on drugs with a low ratio such as paracetamol or antipyrine. This is supported by the greatly prolonged half life of lignocaine in patients with cardiac failure. ${ }^{24}$ Branch et $a l^{12}$ found no difference in the half life of antipyrine between patients with and without evidence of portosystemic shunting who had liver disease of similar severity, suggesting that reduced liver blood flow has little effect on the clearance of antipyrine. On the other hand, treatment with inducing agents such as phenobarbitone greatly reduced the plasma half life of antipyrine, suggesting that enzyme activity in the liver cell is a major determinant of the hepatic clearance of drugs with a low hepatic extraction ratio. In addition, the differences observed in the half lives of the different drugs could be due in part to the varying activities of the different enzyme systems.

Our findings do not allow a distinction to be made between selective impairment of the different drug metabolising enzymes and reduction in hepatic blood flow as an explanation for the observed differences in the half lives of antipyrine, paracetamol, and lignocaine. For drugs with a high hepatic extraction ratio, however, liver blood flow may be more important than enzymatic activity. Whatever the precise mechanisms it is clear that the elimination of some drugs is grossly abnormal in many patients with chronic liver disease. Often there may be severe depression of metabolism resulting in rapid accumulation and serious or fatal toxicity when conventional doses are used, patients with a low serum albumin concentration and a prolonged PTR being most at risk. This should be borne in mind when prescribing drugs for patients with chronic liver disease. It would seem appropriate to start with a reduced dosage when the drug is mainly metabolised by the liver, has a high hepatic extraction ratio, and is being given to patients with severe liver disease.

We gratefully acknowledge the technical help of Mrs I Darrien. This study was supported in part by a grant from the Scottish Home and Health Department. 


\section{References}

1 James, I, British fournal of Hospital Medicine, 1975, 13, 67.

2 Levi, A J, Sherlock, S, and Walker, D, Lancet, 1968, 1, 1275.

${ }^{3}$ Mawer, G E, Miller, N E, and Turnberg, L A, British fournal of Pharmacology, 1972, 44, 549 .

4 Thomson, P, et al, Annals of Internal Medicine, 1973, 78, 499.

5 Klotz, U, et al, Clinical Pharmacology and Therapeutics, 1974, 16, 667.

${ }^{6} \mathrm{Klotz}, \mathrm{U}$, et al, fournal of Clinical Investigation, 1975, 55, 347.

7 Sessions, J T, et al, fournal of Clinical Investigation, 1954, 33, 1116.

${ }^{8}$ Nelson, E, American fournal of the Medical Sciences, 1964, 248, 657.

- Maxwell, J D, et al, Clinical Science, 1972, 43, 143.

${ }^{10}$ Hvidberg, E F, Andreasen, P B, and Ranek, L, Clinical Pharmacology and Therapeutics, 1974, 15, 171.

11 Wilkinson, G R, and Schenker, S, Drug Metabolism Reviews, 1975, 4, 131.

12 Branch, R A, Herbert, C M, and Read, A E, Gut, 1973, 14, 569.

${ }^{13}$ Anderson, P B, et al, European fournal of Clinical Investigation, 1974, 4, 129
14 Vessel, E S, and Page, J G, fournal of Clinical Investigation, 1968, 47, 2657.

15 Davies, D S, and Thorgiersson, S S, Acta Pharmacologica et Toxicologica, 1971, 29, suppl No 3, p 182.

${ }^{16} \mathrm{Kadar}, \mathrm{D}$, et al, Clinical Pharmacology and Therapeutics, 1973, 14, 552.

17 Adjepon-Yamoah, K K, and Prescott, L F, fournal of Pharmacy and Pharmacology, 1974, 26, 889.

18 Prescott, L F, Adjepon-Yamoah, K K, and Roberts, M E, fournal of Pharmacy and Pharmacology, 1973, 25, 205.

19 Prescott, L F, fournal of Pharmacy and Pharmacology, 1971, 23, 807.

${ }^{20}$ Adjepon-Yamoah, K K, Nimmo, J, and Prescott, L F, British Medical Journal, 1974, 4, 387

21 O'Malley, K, et al, British Medical fournal, 1971, 3, 607.

22 Prescott, L F, et al, Lancet, 1971, 1, 519.

${ }^{23}$ Groszmann, R, et al, American fournal of Medicine, 1972, 53, 715.

${ }^{24}$ Prescott, L F, Adjepon-Yamoah, K K, and Talbot, R G, British Medical fournal, 1976, 1, 939.

(Accepted 17 March 1977)

\title{
Immune complexes in Behçet's syndrome and recurrent oral ulceration
}

\author{
B D WILLIAMS, T LEHNER
}

British Medical fournal, 1977, 1, 1387-1389

\begin{abstract}
Summary
Seventeen patients with Behcet's syndrome, 11 with recurrent oral ulceration, and eight controls were studied in an investigation of the part possibly played by immune complexes in the transition from focal oral ulceration to the multifocal syndrome. Changes in the distribution of C3 within the first peak of Sephadex G200 fractionated plasma were found in nine of the 17 patients with Behcet's syndrome $(55 \%)$, three of the 11 patients with recurrent oral ulcers, and none of eight controls. These findings provide indirect evidence that immune complexes are found in the plasma of these patients. Immune complexes were more common in patients with the neuro-ocular type of Behcet's syndrome than in those with the mucocutaneous type, and in those with herpetiform ulcers than in those with major or minor aphthous :ulcers. Immune complexes were also associated with active disease. These findings support the hypothesis that the formation of immune complexes is an important step in the pathogenesis of Behçet's syndrome.
\end{abstract}

\section{Introduction}

Behçet's syndrome is a disease that affects many tissues; the most common manifestations are orogenital ulceration, skin lesions, uveitis, arthralgia, neurological lesions, and vascular thrombosis. The cause of the syndrome is unknown but most of the evidence suggests some abnormality in the immune mechanism. Complement components have recently been

Departments of Medicine and Oral Immunology and Microbiology Guy's Hospital Medical and Dental Schools, London SE1 9RT

B D WILLIAMS, MSC, MRCP, lecturer

T LEHNER, MD, FDS, professor of oral immunology investigated and although $\mathrm{C} 3$ and $\mathrm{C} 4$ concentrations are normal, high levels of total haemolytic complement and $C 9$ have been found in patients with Behçet's syndrome. ${ }^{1-3}$ There is also some evidence that complement consumption by the classical pathway may occur in Behçet's syndrome since low levels of C2, C4, and C3 have been found before an attack of uveitis. ${ }^{1}$ These observations raise the possibility that the complement system might be implicated in the pathogenesis of Behçet's syndrome and recurrent oral ulceration and that immune complexes might play a part in the transition from focal oral ulceration to the multifocal Behçet's syndrome.

\section{Patients and methods}

The series consisted of 17 patients with Behçet's syndrome, 11 with recurrent oral ulceration, and eight controls. Patients with Behçet's syndrome were further classified according to the type of tissues that were affected": four patients had the mucocutaneous type of the syndrome, with orogenital and skin manifestations; four had the arthritic type, with joint involvement and some or all of the mucocutaneous lesions; and nine had the neuro-ocular type with neurological or ocular manifestations, or both, in addition to some or all of the lesions found in patients with the mucocutaneous or arthritic types. The mouth ulcers found in these patients and the 11 with recurrent ulceration were classified into minor aphthous ulcers, major aphthous ulcers, and herpetiform ulcers ..$^{5}$

A specimen of blood was collected from each subject into edetic acid (final concentration $0.01 \mathrm{~mol} / \mathrm{l}$ ). All the samples were coded and the code was broken after completion of the assay. The plasma was separated and either used immediately or stored in small aliquots at $-70^{\circ} \mathrm{C}$. Plasma was fractionated on Sephadex G200, and the concentration of $\mathrm{C} 3$ in the first peak fractions (20-26) was determined by a sensitive haemagglutination inhibition assay. Details of these methods have been published elsewhere. ${ }^{6}$

\section{Results}

The elution profile of control plasma fractionated on Sephadex G200 is shown in Fig 1a. Only a small quantity of $\mathrm{C} 3$ was found in the first peak and it was confined to the last three fractions (fractions 24-26). Most of the C3 was found under the second peak and the position corresponded to its molecular weight of 185000 " The elution profile of plasma obtained from a patient with Behçet's syndrome showed an 